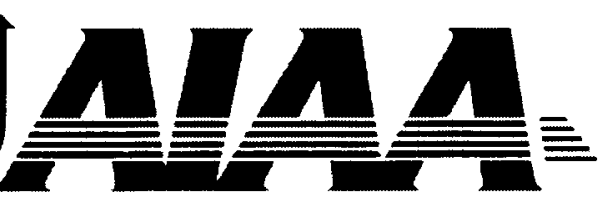

AIAA 2003-3418

Turbulence Model Comparisons for Supersonic Transports at Transonic and Supersonic Conditions

S.M.B.Rivers and R.A.Wahls

NASA Langley Research Center

Hampton, VA

21st AIAA Applied Aerodynamics Conference 23-26 June 2003 / Orlando, FL 


\title{
TURBULENCE MODEL COMPARISONS FOR SUPERSONIC TRANSPORTS AT TRANSONIC AND SUPERSONIC CONDITIONS
}

\author{
S. M. B. Rivers" and R. A. Wahls ${ }^{\dagger}$ \\ Aerodynamics, Aerothermodynamics, and Acoustics Competency \\ NASA Langley Research Center \\ Hampton, Virginia
}

\begin{abstract}
Results of turbulence model comparisons from two studies on supersonic transport configurations performed during the NASA High-Speed Research program are given. Results are presented for both transonic conditions at Mach 0.90 and supersonic conditions at Mach 2.48. A feature of these two studies was the availability of higher Reynolds number wind tunnel data with which to compare the computational results. The transonic wind tunnel data was obtained in the National Transonic Facility at NASA Langley, and the supersonic data was obtained in the Boeing Polysonic Wind Tunnel.

The computational data was acquired using a state of the art Navier-Stokes flow solver with a wide range of turbulence models implemented. The results show that the computed forces compare reasonably well with the experimental data, with the BaldwinLomax with Degani-Schiff modifications and the Baldwin-Barth models showing the best agreement for the transonic conditions and the Spalart-Allmaras model showing the best agreement for the supersonic conditions. The transonic results were more sensitive to the choice of turbulence model than were the supersonic results.
\end{abstract}

"Aerospace Engineer, Configuration Aerodynamics Branch, Member, AIAA

${ }^{\dagger}$ Assistant Head, Configuration Aerodynamics Branch, Associate Fellow, AIAA

This material is declared a work of the U.S. Government and is not subject to copyright protection in the United States.

\section{INTRODUCTION}

Increasing computer capacity and the development of efficient numerical methods enable the solution of the Navier-Stokes equations for practical aerodynamic simulations of advanced configurations such as a next generation supersonic transport. Of crucial importance to the usefulness of such simulations is the physical appropriateness and resulting accuracy of the turbulence model applied; the viability of a next generation supersonic transport is in part based on the ability to predict performance/drag to within one count at design cruise conditions, as well as to predict the onset and progression of separated flow that occurs over a range of angles-of-attack at off-design conditions. The search for a new or improved turbulence model that accurately predicts both attached and separated 3D flow fields is complicated by inherent limitations in the CFD codes that use them such as truncation error, grid density, the type of differencing scheme employed, and, for central-difference schemes, the amount of artificial dissipation added for numerical stability.

During the NASA High-Speed Research (HSR) program multiple studies were executed to assess the performance of various turbulence models. This paper summarizes the results of two investigations performed during the HSR program to assess and compare the ability of multiple turbulence models to accurately simulate flow at transonic and supersonic conditions over relevant supersonic transport configurations. The thin-layer Navier-Stokes solver CFL3D 
(ref. 1) was run using the Baldwin-Lomax (ref. 2) with the Degani-Schiff modifications (B-L) (ref. 3), Baldwin-Barth (B-B) (ref. 4), SpalartAllmaras (S-A) (ref. 5), and Menter's shear stress transport (SST) turbulence models (ref. 6) for the transonic study. The supersonic study also used CFL3D with the S-A, B-L, and $B-B$ models, in addition to a preliminary version of the Gatski/Speziale k- $\omega$ model (ref. 7). Each of these models is briefly described herein. No attempt was made to tune these turbulence models for any specific configuration or condition.

A feature of these studies was the availability of higher Reynolds number wind tunnel data from the National Transonic Facility (NTF) at NASA Langley and the Boeing Polysonic Wind Tunnel (PSWT) for comparison purposes.

\section{TERMS AND ABBREVIATIONS}

$\begin{array}{ll}C_{D} & \text { drag coefficient } \\ C_{L} & \text { lift coefficient } \\ C_{m} & \text { pitching-moment coefficient } \\ \text { L/D } & \text { lift-to-drag ratio } \\ M & \text { freestream Mach number } \\ \text { mac } & \text { mean aerodynamic chord, in. } \\ q & \text { dynamic pressure, psf } \\ \mathrm{Re}_{\mathrm{Ht}} & \text { Reynolds number per foot } \\ \mathrm{Re}_{\mathrm{mac}} & \begin{array}{l}\text { Reynolds number based on mean } \\ \end{array} \\ \mathrm{y}^{+} & \text {aerodynamic chord } \\ \alpha & \text { law-of-the-wall coordinate }\end{array}$

\section{Abbreviations:}

B-L Baldwin-Lomax with Degani-Schiff modifications model

B-B Baldwin-Barth model

Exp experiment

S-A Spalart-Allmaras model

SST Shear Stress Transport model

\section{EXPERIMENTAL APPROACH}

\section{Transonic Conditions}

\section{Facility Description}

Transonic experimental data was acquired in the National Transonic Facility (NTF) at the NASA Langley Research Center. The NTF is a unique national facility that enables tests of aircraft configurations at conditions ranging from subsonic to low supersonic speeds at Reynolds numbers up to full-scale flight values, depending on the aircraft type and size. The facility is a fan-driven, closed-circuit, continuous-flow, pressurized wind tunnel capable of operating in either dry air at warm temperatures or nitrogen from warm to cryogenic temperatures. The test section is $8.2 \mathrm{ft}$ by $8.2 \mathrm{ft}$ in cross section and $25 \mathrm{ft}$ in length. The test section floor and ceiling are slotted (6 percent open), and the sidewalls are solid. Free-stream turbulence is damped by four screens and a 14.95:1 contraction ratio from the settling chamber to the test section. Fan-noise effects are minimized by an acoustic treatment both upstream and downstream of the fan. A detailed assessment of the dynamic flow quality in the NTF is reported in reference 8 , and reconfirmed with more recent measurements shown in reference 9 . The NTF is capable of an absolute pressure range from $15 \mathrm{psi}$ to 125 psi, a temperature range from $-320^{\circ} \mathrm{F}$ to $150^{\circ} \mathrm{F}$, a Mach number range from 0.2 to 1.2 , and a maximum Reynolds number of $146 \times 10^{6}$ per $\mathrm{ft}$ at Mach 1. Typical tests use temperatures ranging from -250 to $120^{\circ} \mathrm{F}$. Further facility details can be found in reference 10 .

\section{Wind Tunnel Model}

Transonic experimental data was acquired using a truncated-aftbody model of a configuration known as the Reference $H$, which was designed by Boeing-Seattle for the HSR program. Figure 1 shows a planform drawing of the model with wing pressure taps and reference locations noted. The model has a cranked-delta wing planform with an aspect ratio of 2.367 , a span of 34.23 inches, a mean 
aerodynamic chord of 22.71 inches, a reference area of $3.436 \mathrm{ft}^{2}$, and pitching moment data have been referenced to the 50 percent mean aerodynamic chord location. The leading edge sweep of the wing is $76 \mathrm{deg}$ inboard of $23 \%$ semispan, $68.50 \mathrm{deg}$ from $23 \%$ to $52 \%$ semispan and 48 deg outboard of $52 \%$ semispan. The leading edge is blunt inboard of $52 \%$ semispan and sharp outboard of $52 \%$ semispan.

The model is shown in Figure 2 mounted in the NTF test section on a straight sting; the sting mounts to a 6-deg offset stub sting which in turn mounts to the facility arcsector resulting in a model angle-of-attack range from -4 to 24 degrees. Further details of the model are provided in references 11-13.

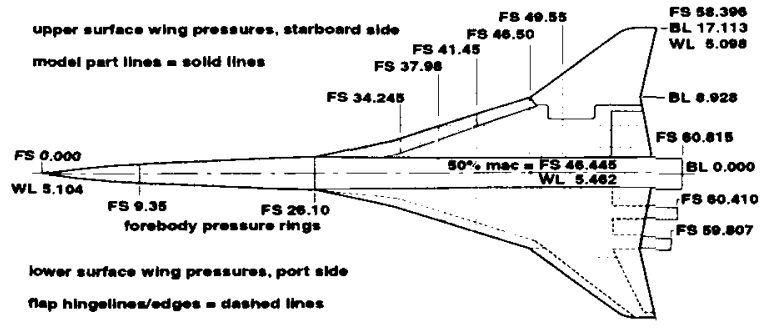

Figure 1. Model drawing with pressure locations (linear dimensions in inches).

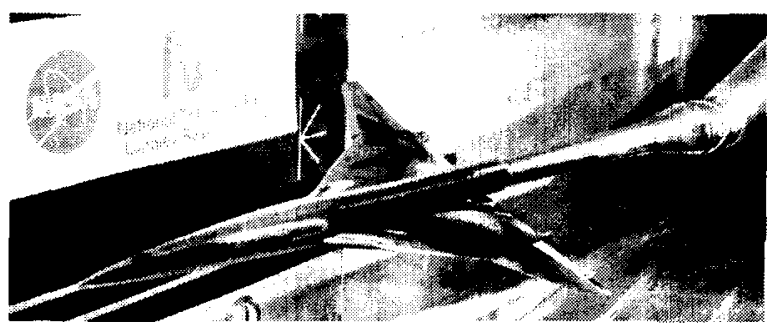

Figure 2. Reference $H$ Model mounted in the NTF.

\section{Test Conditions and Data Quality}

The NTF is a cryogenic, pressure wind tunnel with independent control of pressure, temperature, and fan speed which allow Mach number, Reynolds number, and dynamic pressure to be varied independently. The wind tunnel tests of this model included a variety of configuration, Mach, Reynolds number, and dynamic pressure combinations. Flow conditions used for comparison herein are Mach 0.90 , Reynolds number based on the mean aerodynamic chord of 30 million, and a dynamic pressure of 1005 psf for the wing/body (nacelles off) configuration with all flaps set to zero degrees.

Standard balance, angle-of-attack, and tunnel parameter corrections have been applied. Wall and model support interference effects have not been accounted for in the data; these effects were minimized through model sizing, particularly for conditions below Mach 0.96. The observed variability in the lift, drag, and pitching-moment coefficients was \pm 0.002 , \pm 0.0002 , and \pm 0.0003 , respectively. Reference 12 provides further discussion of data quality.

The significance of the $\mathbf{3 0}$ million Reynolds number test condition for this computational study is the naturally occurring fully turbulent flow observed in the experiment (ref. 12). This reduces uncertainty in the assessment of the turbulence models in two ways: 1) no influence of roughness elements required to force transition, and 2) fully turbulent calculations from the leading-edge are appropriate.

\section{Supersonic Conditions}

\section{Facility Description}

Supersonic experimental data was acquired in the Boeing (formerly McDonnell Douglas) Polysonic Wind Tunnel (PSWT) located in St. Louis, MO. The facility has the highest supersonic Reynolds number capability in the US. The PSWT is an intermittent pressure-toatmosphere blowdown tunnel with two 4 by 4 by $6 \mathrm{ft}$ long test sections; one test section is for supersonic testing, the other for subsonic/transonic testing, and together enable a Mach number range from 0.3 to 5.5. In the supersonic configuration, start-up loads are reduced through the use of downstream ejectors. At the time of the test, the PSWT was not calibrated for Mach 2.4 (HSR program nominal cruise), but was calibrated at Mach 2.48. For the purposes of this investigation, this difference is not significant. A key 
characteristic of this facility is its high-pressure capability that in turn enables the high Reynolds number capability; the maximum Reynolds number of the facility at Mach 2.48 was not attainable due to model load/sting divergence limitations at high dynamic pressure.

\section{Wind Tunnel Model}

Supersonic experimental data was acquired using a $1.675 \%$ scale model of the BoeingLong Beach baseline arrow wing configuration used in the HSR program and designated M2.4-7A. A planform drawing is shown in Figure 3. The wing planform incorporates a leading-edge break at $70 \%$ semi-span and a trailing edge at $30 \%$ semi-span; the planform in these regions has been smoothly faired. The leading-edge sweep is 71 deg inboard and $61.5 \mathrm{deg}$ outboard. The aspect ratio is 1.84 , and at model scale the reference area, mean aerodynamic chord and wingspan are $2.511 \mathrm{sq} \mathrm{ft}, 18.886$ in., and $2.149 \mathrm{ft}$, respectively. The body length is $4.395 \mathrm{ft}$.

Available model components include a wing, a body truncated slightly aft of the wing trailing edge, and four diverter mounted flow through nacelles; only the wing-body configuration was tested in this investigation. Neither the wing nor the body was instrumented for surface pressure measurements; the result was a stiffer, stronger wing less susceptible to static aeroelastic deformation under load as compared to an instrumented wing. The model, shown in Figure 4, was mounted on a six-component strain gage balance, which in turn was supported by a straight sting; cavity pressures were measured and corrections applied.

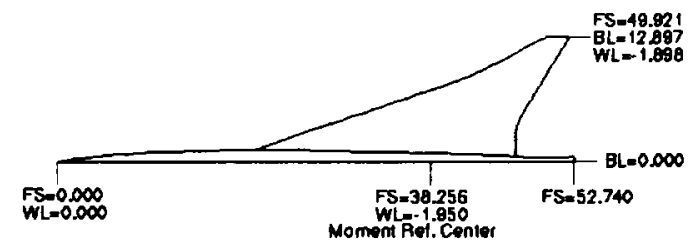

Figure 3. Planform view of the M2.4-7A model (linear dimensions in inches).

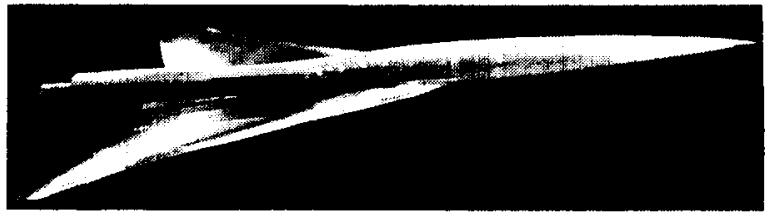

Figure 4. M2.4-7A model mounted in the PSWT.

\section{Test Conditions and Data Quality}

Nominal test conditions were Mach $=2.48$, Reynolds number from 5 to 15 million per foot (corresponding to dynamic pressures from 1000 to $3000 \mathrm{psf}$ at a total temperature of $100 \mathrm{deg}$ F), and an angle-of-attack range from -3 to 3 deg. The highest Reynolds number attained was 14.21 million per foot.

The primary objective of the experimental investigation was an assessment of trip drag methods. The only configuration variable was the transition trip. Trip dots were used rather than grit as dots were the most prevalent in HSR testing. On the wing, 5 trip heights (k) ranging from 0.0079 to 0.0149 inches plus the trip off (free transition) condition were used. The trip location was 0.6 in. streamwise from the leading edge. On the forebody, a ring of dots $1.0 \mathrm{in}$. from the nose was used in addition to a trip off case. The trip-free configuration and a configuration with the nose trip on and a 0.0109 in. wing trip were the most heavily tested.

Data quality for this investigation was assessed in two ways: 1) a theoretical uncertainty analysis focusing on systematic or bias errors, and 2) a repeatability assessment based on data acquired throughout the test. Bias errors are important when comparing absolute levels between the experiment and computation; drag-coefficient bias uncertainty was on the order of 1.5 to 3 counts, with the higher uncertainty at higher angles-of-attack. Good repeatability was especially important for this trip drag study where highly reliable incremental results were critical. The observed variability of the drag coefficient was \pm 0.8 counts over short periods of time, and \pm 1.6 counts over the complete test. Both bias uncertainties and observed variability of lift and pitching-moment data was small. 
An advantage of using the PSWT is the ability to apply both variable trip height and variable Reynolds number methods to assess trip drag, and the ability to anchor data at a relatively high Reynolds number (14.21 million per foot) that enabled nearly fully turbulent flow. The majority of the test data was acquired near 5.26 million Reynolds number per foot, which was the primary condition for which trip drag was assessed. The correction of the fixed-transition experimental data to fully turbulent conditions accounts for +1 drag count for a laminar leading-edge run, and -2.9 and -5.0 counts of trip drag at minimum drag and cruise conditions, respectively, for the baseline trip height ( $k=0.0109$ in.). Computations are compared to free transition, fixed transition, and corrected-to-fully-turbulent flow data.

\section{COMPUTATIONAL METHOD}

\section{Flow Solver}

The flow solver used in this study was version 4 of the Navier-Stokes code known as CFL3D, which is described in detail in reference 1 . This code, developed at NASA Langley, solves the 3-D time-dependent thin-layer Navier-Stokes equations with a finite-volume formulation. A second-order accurate upwindbiased spatial differencing scheme is utilized for solving these equations. Roe's fluxdifference splitting (ref. 14) is used to construct the upwind differences for the convective and the pressure terms. The spatial derivatives are written conservatively as a flux balance across the cell, and the shear stress and heat transfer terms are centrally differenced. Spatial approximate factorization and Euler backward integration after linearization in time results in the solution through $5 \times 5$ block-tridiagonal matrix inversions in three directions. An approximate diagonal form of the spatial factors is employed to reduce computational time. Convergence acceleration is obtained by using a multigrid full-approximation scheme and mesh sequencing for flow initialization.

\section{Turbulence Models}

\section{Baldwin-Lomax with Degani-Schiff modification.}

The Baldwin-Lomax two layer algebraic turbulence model is described in detail in reference 2. This model was used widely throughout the CFD community until the mid1990's; its capabilities and limitations are well known. In short, it is generally considered a good model for the prediction of attached flows, but is deficient for flows with any significant separated regions. In particular, the Baldwin-Lomax model tends to predict shocks too far downstream for separated transonic flows over aerodynamic configurations. Degani and Schiff, ref. 3, modified the original Baldwin-Lomax model to extend the model in a rational manner to permit an accurate determination of the viscous length scale for high-angle-of-attack flows in regions of crossflow separation, where a strong leeward vortical flow structure exists. Throughout this paper, the Baldwin-Lomax model with the Degani-Schiff modifications is abbreviated as B-L.

\section{Baldwin-Barth.}

The Baldwin-Barth (B-B) turbulence model is described in detail in reference 4 . This model is a one-equation turbulence model derived from a simplified form of the $k-\varepsilon$ equations. The model solves a partial differential equation (PDE) over the whole field for the turbulent Reynolds number, which is directly related to the kinematic eddy viscosity $v_{t}$. In this formulation of the B-B turbulence model, the thin-layer assumption has been used for the source term. The PDE is solved implicitly using 3-factor approximate factorization, with first-order upwind differencing used on the advective terms. Local time stepping is employed to accelerate convergence.

\section{Spalart-Allmaras.}

The Spalart-Allmaras (S-A) turbulence model is a one-equation turbulence model derived "using empiricism and arguments of dimensional analysis, Galilean invariance, and selective dependence on the molecular 
viscosity." Further details can be found in reference 5 . The S-A model is very similar in form to the B-B model, although the S-A model includes a destruction term that is not present in the other model. This lack of a destruction term in the B-B model is responsible for a mild inconsistency in modeling isotropic turbulence and could also invalidate the model in the class of shear flows in which $v_{t}$ decreases such as an axisymmetric wake. The PDE is solved using the same implicit method used in the B-B model.

\section{Menter's SST.}

The Menter Shear-Stress Transport (SST) turbulence model is a modified version of the $k$ - $\omega$ two-equation turbulence model. This model is based on Bradshaw's assumption that the principal shear-stress is proportional to the turbulent kinetic energy, which is introduced into the definition of the eddyviscosity. This model transforms a $k-\varepsilon$ model into a $k-\omega$ formulation. This model is described in greater detail in reference 6.

\section{Gatski-Speziale k- $\omega$ model.}

The EASM (Explicit Algebraic Stress Model) is derived directly from the modeled transport equation for the Reynolds stress tensor, with isotropic dissipation rate and an assumed linear form for the pressure-strain correlation tensor. An algebraic relation results by assuming an equilibrium hypothesis and a functional form for diffusive effects. Next, an explicit relation can be derived in terms of an $n$-term basis. The model can be cast in twoequation form (such as $k-\varepsilon$ or $k-\omega$ ), and solved at little additional expense. It yields an explicit representation for the Favre-averaged correlation tensor, and is fully nonlinear. In CFL3D, a three-term integrity basis is employed. Constants from the SpezialeSarkar-Gatski pressure-strain correlation model are used. In the originally developed EASM approach, the value of $P / \varepsilon$ (where $P$ is production and $\varepsilon$ is turbulent dissipation rate) is assumed to be a constant. With this assumption, $\mathrm{C} \mu$ (which appears in the relation that determines the eddy viscosity) is determined through an explicit relation, which is typically regularized to avoid possible numerical problems. In the more recent (and now recommended) EASM methodology, the value of $P / \varepsilon$ is allowed to vary. When this is done, $\mathrm{C}_{\mu}$ must be determined through the solution of a cubic equation. A full description is available in reference 7 . The preliminary implementation of this model was used for this study.

\section{Grid Generation}

\section{Reference H Configuration}

The grid generated about the NTF $2.2 \%$ scale Reference $\mathrm{H}$ model was a single block $\mathrm{C}-\mathrm{O}$ (C in the streamwise direction and $O$ in the spanwise direction) topology grid that defined both the wing/body configuration and the sting. This grid had 133 points in the spanwise direction, 249 points in the streamwise direction and 81 points in the normal direction. The total number of grid points was 2,682,477. The grid distribution normal to the surface corresponds to a nondimensional $y^{+}$value of approximately 1.0 for $M=0.90$ and $R e_{\text {mac }}$ $=30 \times 10^{6}$. The farfield boundary extends to $20 \mathrm{mac}$ in the circumferential, upstream, and downstream (of the wing/body configuration) directions. Figure 5 shows the volume grid for this configuration.

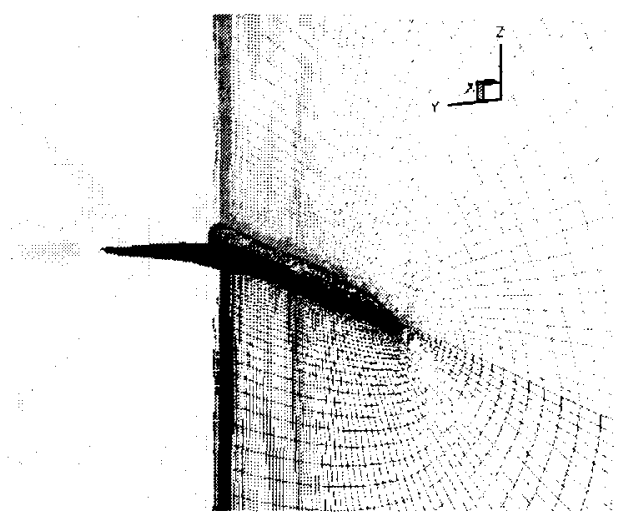

Figure 5. Volume grid of the Reference H $2.2 \%$ Model.

\section{M2.4-7A Configuration}

A single block $\mathrm{C}-\mathrm{O}$ topology grid was used to model the M2.4-7A geometry. This grid had 93 points in the spanwise direction, 241 points in 
the streamwise direction and 65 points in the normal direction to give a total number of grid points of $1,456,845$. The grid distribution normal to the surface corresponds to a nondimensional $\mathrm{y}^{+}$value of approximately 1.0 for the baseline conditions.

\section{RESULTS AND DISCUSSION}

\section{Comparisons at Transonic Conditions}

Multiple turbulence models, the equilibrium model of Baldwin-Lomax with the DeganiSchiff modification, the one-equation BaldwinBarth model, the one-equation SpalartAllmaras model and Menter's two-equation Shear Stress Transport model, were used to simulate flow over the HSR $2.2 \%$ Ref. $H$ geometry at $M=0.90, R e_{m a c}=30 \times 10^{6}$, and at three angles-of-attack, 1, 5, and 10 degrees; the three angles-of-attack are representative of minimum drag, cruise, and high angle conditions, respectively. In this investigation, all calculations assume fully turbulent flow, which is consistent with experimental data at this condition (see ref. 12).

The solutions were considered converged when the drag coefficient changed less than one count over 100 iterations and the residual was decreased by at least three orders of magnitude. Figure 6 and Figure 7 show a typical residual history and drag convergence for $\alpha=5 \mathrm{deg}$. These histories are typical of all of the turbulence models and angles-of-attack.

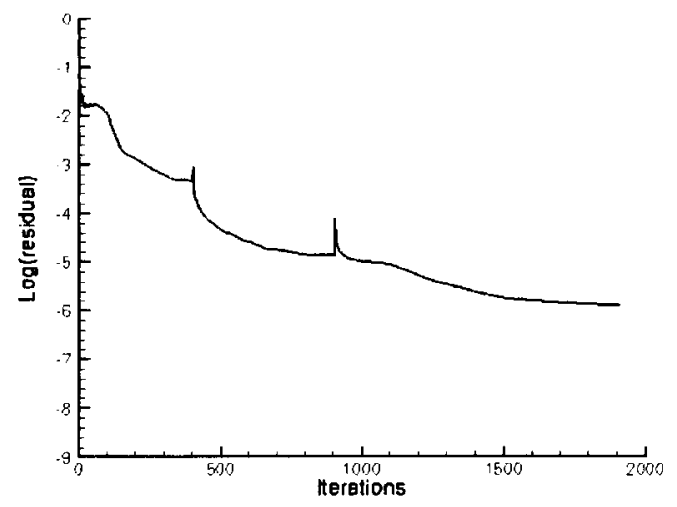

Figure 6. Typical Residual History for the Reference H 2.2\% NTF Model.

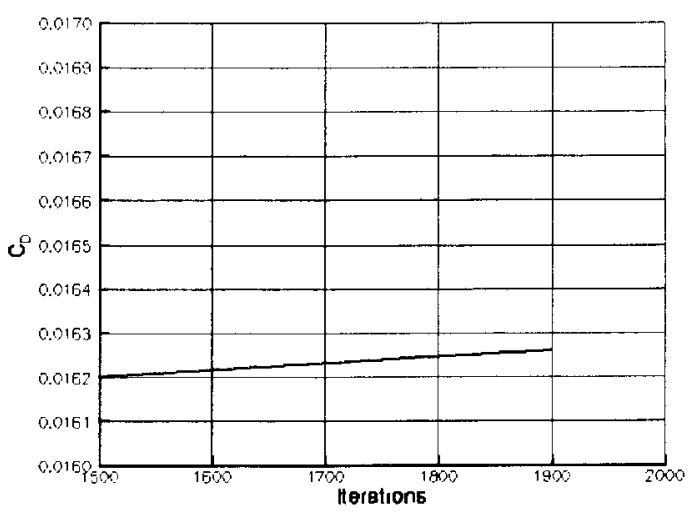

Figure 7. Typical Drag Convergence for the Reference H 2.2\% NTF Model.

Figure 8 shows the drag polar for the four turbulence models and the experimental data. At $\alpha=1.0 \mathrm{deg}, \mathrm{S}-\mathrm{A}$ is the only turbulence model that overpredicts the drag level. At the design point, $\alpha=5.0 \mathrm{deg}$, $B-B$ is approximately 1 drag count low, with S-A, SST, and B-L being 4,6 , and 13 drag counts low, respectively. At $\alpha=10.0 \mathrm{deg}$, all of the models predict the drag levels low.

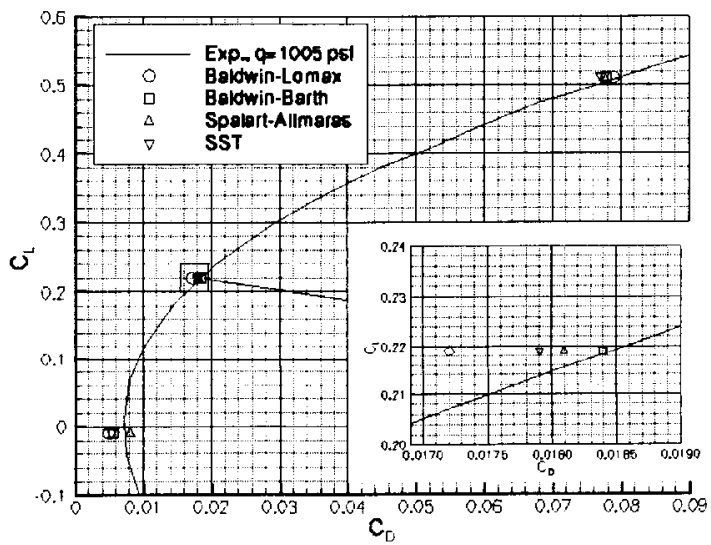

Figure 8. Drag Polar for the NTF Ref. $\mathrm{H}$ at $M=0.90, R_{\text {mac }}=30 \times 10^{6}$.

Figure 9 shows the lift curve for the four turbulence models and the experimental data. At $\alpha=1.0 \mathrm{deg}$, all of the models are slightly higher than the experimental data. At the design point, $\alpha=5.0 \mathrm{deg}$, B-L is closer to the experimental lift curve than the other three models; at $\alpha=10.0 \mathrm{deg}, \mathrm{B}-\mathrm{L}$ is also closer to the experimental lift curve than the other three 
models. It should be noted that the computations were for the rigid, 1-g geometry while the wind tunnel model is flexible and does experience a wing-tip wash-out under load (ref. 12). The effect of the wash-out under load is a reduced lift at constant angleof-attack relative to the rigid shape; this effect is not accounted for in the comparisons shown.

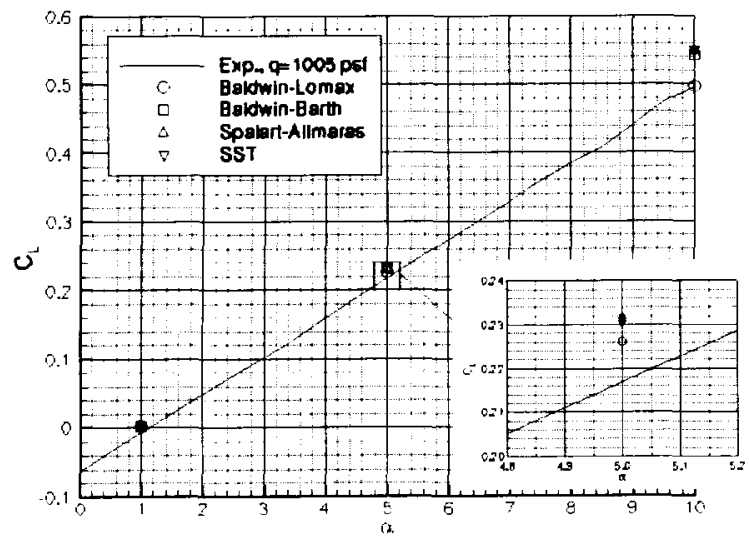

Figure 9. Lift Curve for the NTF Ref. $\mathrm{H}$ at $M=0.90, R_{\text {mac }}=30 \times 10^{6}$.

The lift-to-drag ratios for the four turbulence models and the experimental data are shown in Figure 10. This figure shows that at $\alpha=1.0$ deg, all four of the models come close to matching the experimental value. At $\alpha=5.0$ deg, B-B matches the experimental data, while the other three models predict the L/D values high. At $\alpha=10.0 \mathrm{deg}$, all of the turbulence models come close to matching the LD values.

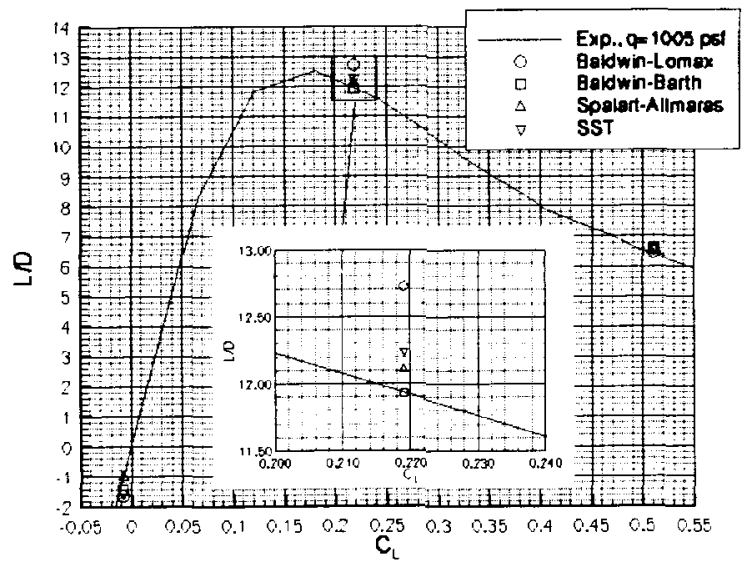

Figure 10. Lift-over-Drag Curve for the NTF Ref. $H$ at $M=0.90, R_{\text {mac }}=30 \times 10^{6}$.
Figure 11 shows the pitching moment curves for the four turbulence models and the experimental data. At $\alpha=1.0 \mathrm{deg}$, all of the models underpredict the pitching moment (predictions are more nose-down than experiment). At $\alpha=5.0 \mathrm{deg}$, all of the models again underpredict the pitching moment, but $B-L$ comes the closest to the experimental values. At $\alpha=10.0 \mathrm{deg}$, all of the models again underpredict the pitching moment, but $B-L$ comes the closest to the experimental values. As mentioned previously, accounting for the wing-tip wash-out effect of the flexible wind tunnel model relative to the rigid computations would tend to improve the comparisons.

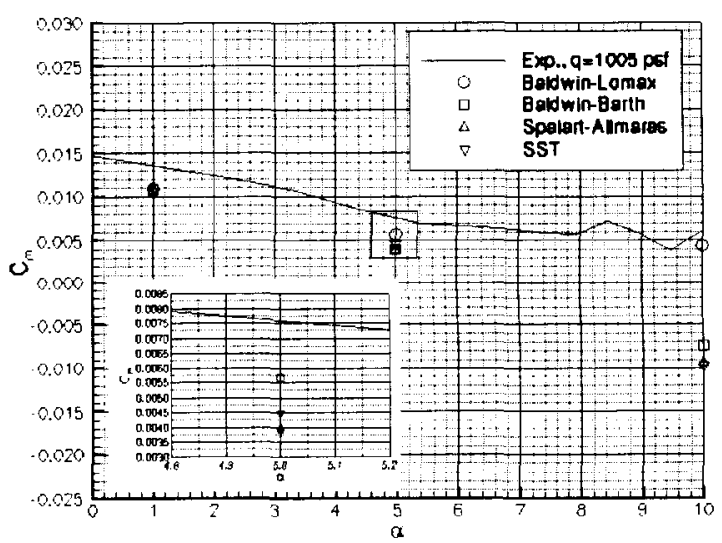

Figure 11. Pitching Moment Curve for the NTF Ref. $H$ at $M=0.90, R_{\text {mac }}=30 \times 10^{6}$.

The computed wing pressure distributions discussed in reference 15 indicated that B-L agreed the best with the experimental data at $\alpha=5.0$ deg while the drag data in Figure 8 indicate that the B-B model agrees somewhat better with experiment at $\alpha=5.0$ degrees. This discrepancy is believed to be caused by a difference in the viscous drag components of the turbulence model results. The $B-L$ turbulence model viscous drag component results are approximately 10 drag counts lower than the other three models at all three angles-of-attack. At $\alpha=10.0 \mathrm{deg}$, the pressure component of drag for B-L is approximately 60 drag counts lower than the other three models, which can account for the results seen at this angle-of-attack. Note also that the 
equivalent flat plate viscous drag is 0.0064 for $M=0.90$ and $R e_{\text {mac }}=30 \times 10^{6}$, which is $7-17$ counts higher than the computations herein. Figure 12 shows that if the flat plate equivalent viscous drag component is substituted for the computational viscous drag component, the computational data are more consistent between turbulence models, and agree better overall with the experimental data.

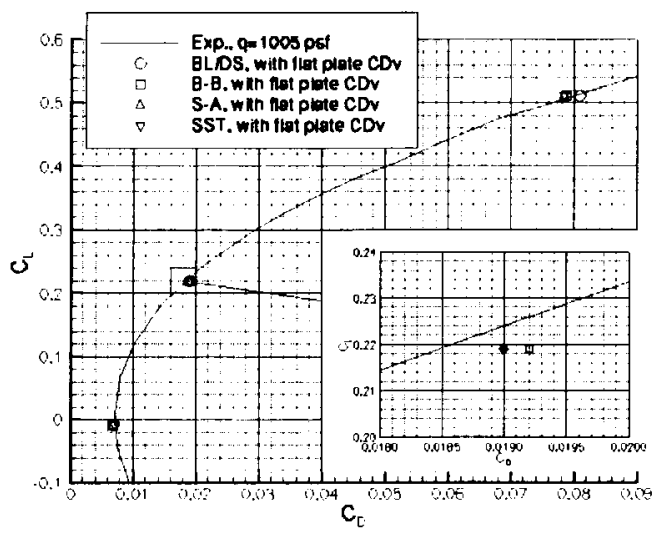

Figure 12. Drag Polar using flat plate equivalent viscous drag instead of computational viscous drag component for the NTF Ref. $\mathrm{H}$ at $M=0.90, \mathrm{Re}_{\mathrm{mac}}=30 \times 10^{6}$.

These results show that the computed forces and moments compared reasonably well with the experimental data, with the B-L and B-B models showing the best agreement. None of the turbulence models predict the experimental flow well at all of the conditions tested herein. B-L seems to give the best agreement with the force data at the higher angles-of-attack, while B-B agrees better with the force data at the lower angles-of-attack. Also, the substitution of the theoretical equivalent flat plate viscous drag for the Navier-Stokes computed viscous drag significantly improves the consistency of results between turbulence models and the overall agreement between the computational and the experimental drag data.

\section{Comparisons at Supersonic Conditions}

Four turbulence models, the equilibrium model of Baldwin-Lomax with the Degani-Schiff modifications, the one-equation Baldwin-Barth model, the one-equation Spalart-Allmaras model and a preliminary version of the Gatski/Speziale k- $\omega$ model, were used to perform runs for the M2.4-7A geometry at a $M=2.48, \operatorname{Re}_{\mathrm{tl}}=5.26 \times 10^{6}$, and at two angles-ofattack, -1 and 2 degrees, representative of near minimum drag and cruise conditions, respectively. In this investigation, it is assumed that the entire boundary layer flow is turbulent, and are compared to free-transition, fixed-transition, and corrected-to-fullyturbulent experimental data. The solutions were considered converged when the drag coefficient changed less than one drag count over 100 iterations and the residual was decreased by at least three orders of magnitude. Typical residual histories and drag convergence plots are shown in Figure 13 and Figure 14, respectively.

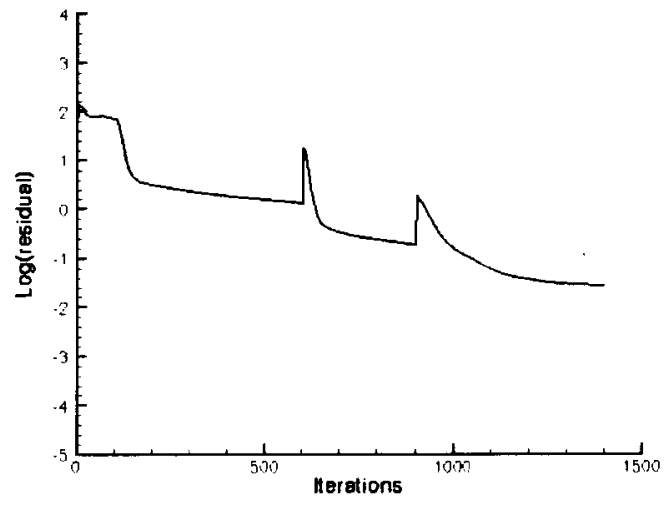

Figure 13. Typical Residual history for the M2.4-7A model.

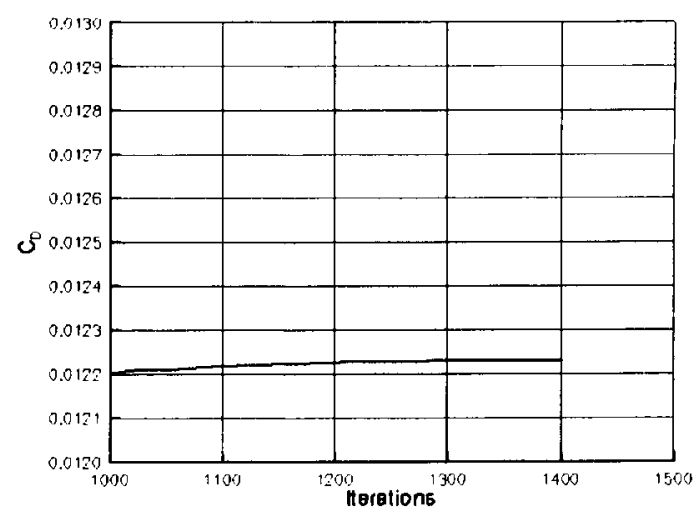

Figure 14. Typical Drag Convergence for the M2.4-7A model. 
The drag polar is shown in Figure 15. This figure shows the drag polar for two experimental conditions (fixed and free transition) and the four different turbulence models at Reynolds number per foot $=5.26$ million and Mach 2.48. There is also one point on each of the enlarged figures showing an experimental value corrected to the fully turbulent condition. Note the lower drag of the free transition data, indicating the presence of significant laminar flow. Also, note that the fixed and free transition experimental data bracket the fully turbulent computational results, indicating the presence of trip drag in the fixed transition experimental data. As the figure shows, Spalart-Allmaras agrees the best with the "fully turbulent" experimental data near minimum drag, and Baldwin-Barth agrees the best near cruise, with SpalartAllmaras over predicting the drag by only 2 counts. In general, there is less difference in predicted drag between turbulence models here than in the transonic case previously shown.

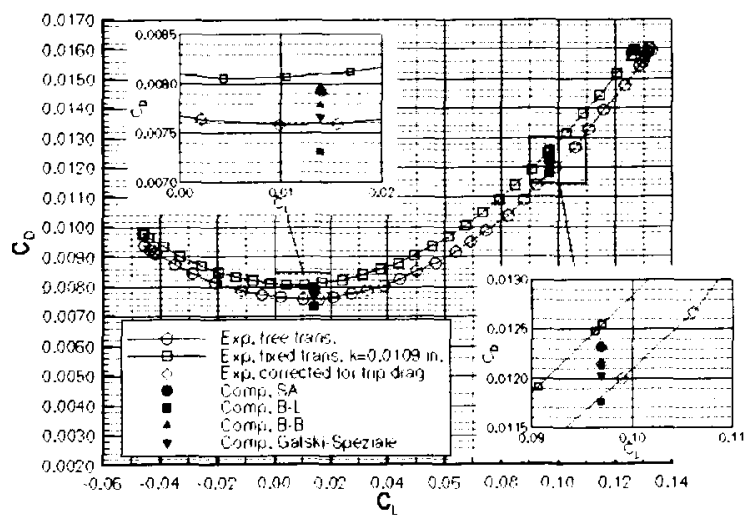

Figure 15. Drag Polar for the M2.4-7A configuration at $M=2.48, R_{n}=5.26 \times 10^{6}$.

Another result, shown in Figure 16, indicates that at $\alpha=-1.0$ deg (near minimum drag), all of the turbulence models predict the same lift, which is in between the free and fixed transition experimental data, as expected. At $\alpha=2.0 \mathrm{deg}$ (near cruise), all of the turbulence models again predict the same lift, but lower than both the experimental values.

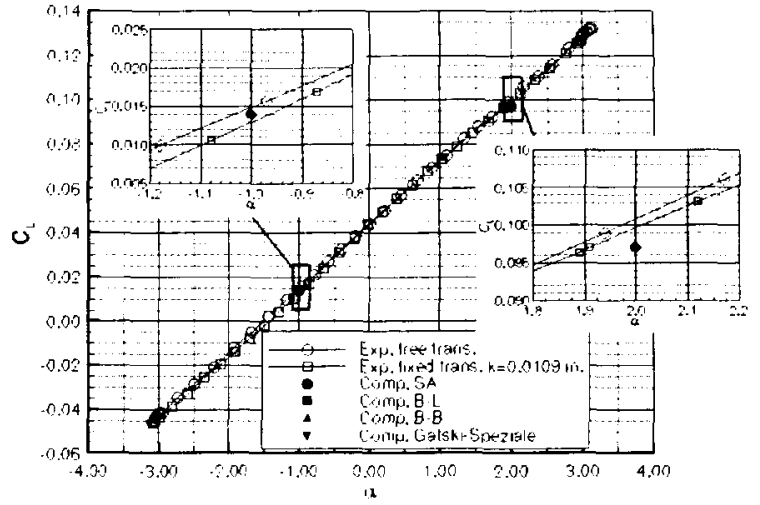

Figure 16. Lift Curve for the M2.4-7A configuration at $M=2.48, R_{\mathrm{ft}}=5.26 \times 10^{6}$.

The pitching moment curves, shown in Figure 17, show that all of the turbulence models predict the same pitching moment values at both $\alpha=-1.0$ and $2.0 \mathrm{deg}$. A slight rotation seen in the $C_{m} / C_{L}$ curve is consistent with a flexible model (experiment) versus a rigid model (CFD).

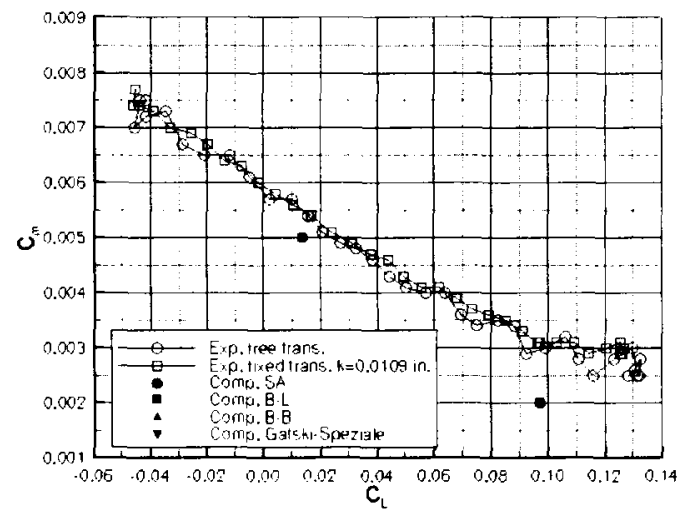

Figure 17. Pitching Moment Curve for the M2.4-7A configuration at $M=2.48$, $\mathrm{Re}_{\mathrm{h}}=5.26 \times 10^{6}$. 


\section{CONCLUDING REMARKS}

Multiple turbulence models have been evaluated for transonic and supersonic flow conditions for realistic supersonic transport configurations using the thin-layer, upwind, Navier-Stokes flow solver known as CFL3D. The turbulence model study showed that the computed forces, moments and pressures (where available, ref. 15) compared reasonably well with the experimental data, with the B-L and B-B models showing the best agreement for the transonic study and the S-A model showing the best agreement for the supersonic study. The sensitivity to the turbulence model was larger in the transonic case than the supersonic case.

\section{REFERENCES}

1. Thomas, J., Krist, S., and Anderson, W., "Navier-Stokes Computations of Vortical Flows Over Low-Aspect-Ratio Wings," AIAA Journal, Vol. 28, No. 2, pp. 205-212, 1990.

2. Baldwin, B., and Lomax, H., "Thin Layer Approximation and Algebraic Model for Separated Turbulent Flow," AIAA 78-257, 1978.

3. Degani, D., Schiff, L.B., and Levy, Y., "Physical Considerations Governing Computation of Turbulent Flows Over Bodies at Large Incidence," AIAA Paper 90-0096, AIAA 28th Aerospace Sciences Meeting, Jan. 1990.

4. Baldwin, B., and Barth, T., "A OneEquation Turbulent Transport Model for High Reynolds Number Wall-Bounded Flows," NASA TM-102847, 1990.

5. Spalart, P., and Allmaras, S., "A OneEquation Turbulence Model for Aerodynamic Flows," AIAA 92-0439, 1992.
6. Menter, F.R., "Two-Equation EddyViscosity Turbulence Models for Engineering Applications," AIAA Journal, Vol. 32, No. 8, pp. 1598-1605, 1994.

7. Abid, R., Rumsey, C., and Gatski, T., "Prediction of Nonequilibrium Turbulent Flows with Explicit Algebraic Stress Models," AIAA Journal, Vol. 33, No. 11, pp.2026-2031, November 1995.

8. Igoe, W.B.: "Analysis of Fluctuating Static Pressure Measurements in the National Transonic Facility," NASA TP-3475, March 1996.

9. Bobbitt, C.W., Hemsch, M.J., and Everhart, J.L.: "NTF Characterization Status," AIAA Paper 2001-755, January 2001.

10. Fuller, D.E.: "Guide for Users of the National Transonic Facility," NASA TM-83124, 1981.

11. Owens, L.R., and Wahls, R.A.: "Reynolds Number Effects on a Supersonic Transport at Subsonic, High-Lift Conditions," AIAA Paper 2001-0911, January 2001.

12. Wahls, R.A., Owens, L.R., and Rivers, S.M.B.: "Reynolds Number Effects on a Supersonic Transport at Transonic Conditions," AIAA Paper 2001-0912, January 2001.

13. Owens, L.R., Wahls, R.A., Elzey, M.B., and Hamner, M.P.: "Reynolds Number Effects on theStability \& Control Characteristics of a Supersonic Transport," AIAA Paper 20020417, January 2002.

14. Roe, P., "Approximate Riemann Solvers, Parameter Vectors, and Difference Schemes," Journal of Computational Physics, Vol. 43, pp. 357-372, 1981.

15. Rivers, Melissa B.; and Wahls, Richard A.: "Turbulence Model Comparisons for a HighSpeed Aircraft. NASA TP-1999-209540, December 1999. 